\title{
Combate à obesidade: uma análise da legislação brasileira
}

\author{
Luiz Carlos Rigo* \\ Cezar Barbosa Santolin**
}

\begin{abstract}
Resumo: Este ensaio teve como objetivo analisar como a obesidade vem sendo tratada na legislação brasileira. O estudo situa-se no campo da "biopolítica" e utilizou como metodologia a Análise de Discurso (AD) foucaultiana. O corpus empírico constituiu-se de uma busca pelas palavras-chave obesidade e sobrepeso no site Jusbrasil, onde foram encontradas 46 leis. A análise desse material apontou que se sobressai uma tendência à culpabilização do sujeito obeso, à incitação ao tratamento médico e uma ênfase discursiva no "combate" à obesidade, em detrimento à garantia dos direitos sociais do grupo.
\end{abstract}

Palavras-chave: obesidade. legislação como assunto. Ciências humanas. Direitos humanos

\section{INTRODUÇÃO}

Recentemente os brasileiros puderam acompanhar através de noticiários o caso de cidadãos que haviam sido reprovados em um concurso para professor da rede pública de ensino do Estado de São Paulo após a perícia médica, sob a alegação de obesidade. Após a interferência da Ordem dos Advogados do Brasil e de denúncias feitas em vários meios de comunicação, o governo estadual optou por reavaliar as 304 pessoas que haviam sido reprovadas por diversos motivos na perícia médica, das quais 223 foram consideradas, desta vez, aptas. Daquelas que haviam sido reprovadas por obesidade -

\footnotetext{
'Programa de Mestrado em Educação Física. Universidade Federal de Pelotas, Pelotas, RS, Brasil. E-mail: Icrigo@terra.com.br

"Programa de Pós-graduação de Educação Física da Universidade Federal de Pelotas (UFPEL). Pelotas, RS, Brasil. E-mail: cezarsantolin@hotmail.com
} 
mais de 50 pessoas - 38 foram aprovadas na segunda avaliação. Ainda assim, 14 pessoas permaneceram reprovadas por esse motivo (REAVALIADOS..., 2011).

$\mathrm{O}$ acontecimento suscitou discussões dentro da área do direito. Guglinski (2011) e Oliveira Junior (2011), por exemplo, denunciaram a inconstitucionalidade da ação. Apesar das muitas críticas em relação aos critérios e técnicas de avaliação utilizada para a classificação, a obesidade é considerada oficialmente uma doença para a classe médica e foi essa a alegação sustentada pelos profissionais que reprovaram os sujeitos.

Muitas vezes, como nesse caso, é através do sistema de perícias médicas que o discurso da saúde pode adentrar o universo jurídico, como apontado por Foucault (2002). Entretanto, a introdução desse saber-poder no meio legal pode também ser mais explícita, através de leis.

Independentemente do meio, a relação entre o discurso da saúde e o jurídico deveria ser vista com cautela pela sociedade, pois pode suprimir os direitos constitucionais dos sujeitos, como no caso supracitado. Nesse sentido, cabe também aos membros da sociedade - principalmente ao meio acadêmico vinculado às pesquisas da área da saúde - estar atentos à forma que o meio jurídico tem se apropriado dos discursos do campo da saúde. Desse modo, o presente estudo teve por objetivo central fazer uma análise crítica sobre como a legislação brasileira trata a obesidade, bem como problematizar alguns efeitos políticos e sociais resultantes dessa representação e produção conceitual da obesidade.

Esse estudo insere-se no campo temático que Foucault (1996a) identificou como "biopoder". Conceito formulado por esse autor para se referir as relações de poder que emergem na segunda metade do século XX e tem como objetivo buscar um maior controle sobre as populações, constituindo uma "biopolítica" (FOUCAULT, 2008). As formulações teóricas acerca do "biopoder" e da "biopolítica" foram retomadas por outros autores, como Pelbart (2003), tendo como referência a própria sociedade brasileira. Pelbart (2003) concebe a 
biopolítica como campo constituído também de micro-resistências ao biopoder, que se configura a partir das relações de poder que emergem e constituem as novas formas de vida da sociedade contemporâneas.

\section{Considerações MEtOdolóGICAS}

A metodologia utilizada para o estudo foi a Análise de Discurso (AD) na perspectiva que a concebe Michel Foucault (1996; 1995; 1998). Foucault chama a atenção para o fato de como o discurso extrapola a dimensão estrutural da linguagem e pode adquirir um sentido político, tornando-se um enunciado. E ressalta que o enunciado "[...] não se dá de forma tão manifesta quanto uma estrutura de gramática ou lógica". Ele "não é visível e não é oculto" (FOUCAULT, 1995, p. 125-126).

Como apresenta Gregorin (2004), para Foucault o discurso é uma prática (prática discursiva) que a partir de determinados regimes de verdades não apenas representa, mas também constitui os objetos e o sujeito. É nesse sentido que iremos analisar o discurso legal (leis) referente à obesidade constituinte da legislação brasileira, atentando para os efeitos produzidos por ele.

O corpus empírico do estudo proveio do site Jusbrasil ${ }^{1}$ (2011), onde, numa busca pelas palavras-chave obesidade e sobrepeso, foram encontradas 46 leis. Pelo fato de haver um grande número de leis referenciadas no trabalho, optou-se por explicitar seus respectivos números em notas de rodapé, acrescentado nas referências somente o endereço do Jusbrasil (2011) e as leis que tiveram passagens citadas diretamente no texto.

\footnotetext{
${ }^{1} \mathrm{~A}$ home page tem como objetivo reunir processos, leis e portarias de todas as esferas do Sistema Jurídico Brasileiro, disponibilizando gratuitamente acesso a mais de 50 milhões de documentos aos cidadãos brasileiros. A escolha desse site deu-se, principalmente, pela amplitude e pela representatividade no campo da jurisdição brasileira. Em 2007, a homepage foi premiada internacionalmente como uma das dez melhores alternativas de acessibilidade e organização em pesquisas jurídicas na internet.
} 


\section{NASCIMENTO DA OBESIDADE: A PATOLOGIZAÇÃO DOS GORDOS}

No século XVIII, os termos corpulento, gordo ou obeso eram utilizados como sinônimos para referir-se a uma condição condenada estética e moralmente. Ao longo do século XIX, entretanto, ocorre a emergência dentro da área médica de um discurso que tenta transformar a condição numa patologia. Os esforços alcançam poucos êxitos até o início do século XX, quando o conceito de risco, difundido por empresas de seguros e utilizado por estudos epidemiológicos, veio a mudar o status daqueles que eram considerados obesos (OLIVER, 2006).

A partir de 1948, ano de criação da Organização Mundial da Saúde (OMS), a obesidade - que passará a ser definida em relação ao Índice de Massa Corporal (IMC) - passou a ser considerada oficialmente uma patologia, integrando a Classificação Internacional das Doenças (CID).

Ainda assim, esse novo status patológico parecia não ser motivo suficiente para transformar a saúde individual numa preocupação pública passível de intervenção, principalmente, estatal. Com intuito de contornar essa esfera individual, muitos estudos sobre o assunto trazem os prejuízos financeiros causados pela obesidade e o impacto orçamentário na saúde pública (COLDITZ; MARIANI, 2003; HALPERN, 1998). O objetivo maior desses estudos parece ser apenas o de outorgar ao poder público o direito de reivindicar a antropometria do sujeito como interesse social.

A incitação do medo provocada pelo conceito de risco associado a uma noção moral, puramente abstrata, de qualidade e expectativa de vida ajuda a forjar no corpo social a verdade de que os obesos não somente são doentes, mas que eles têm a obrigação de emagrecer, inclusive pelos prejuízos que, supostamente, acarretariam aos cofres públicos.

Enquanto não houve um detalhamento quantitativo específico, a "nova patologia" não teve uma grande repercussão social. Somente após o estabelecimento de critérios baseados no IMC, em 1998, a 
condição foi alçada a uma situação em que os sujeitos passaram a ser classificados oficialmente pelas autoridades em saúde como doentes. Na atualidade, a partir de uma classificação das biociências, que colocam a obesidade como doença, o tema tornou-se palco de inúmeras controvérsias éticas e políticas, que vão desde campanhas que reivindicam direitos básicos de cidadania até a denúncia de violência (bullying), preconceito, estigmatização e segregação social.

\subsection{MAPEANDO A OBESIDADE NA LEGISLAÇÃO BRASILEIRA}

Em consulta ao site Jusbrasil (2011), foram encontradas, ao todo, 46 leis em que constavam as palavras "obesidade" ou "sobrepeso", das quais 32 eram municipais, 13 estaduais e 1 nacional. Os estados do Rio de Janeiro e de São Paulo foram os que tiveram maior número de legislações estaduais e municipais, somando 16 e 14 , respectivamente.

As leis encontradas foram promulgadas no período entre 1999 e 2010, sugerindo que a definição de parâmetros técnicos pela OMS (1998) pode ter influenciado os representantes políticos que propuseram tais leis. Em algumas delas, inclusive, a definição da OMS (1998) está inclusa - principalmente, quando se refere à obesidade dita mórbida. Já em outras, apesar da palavra "obeso" ser utilizada, recomenda-se que se considere, simplesmente, o tamanho da massa corporal ${ }^{2}$, sugerindo que o termo é, muitas vezes, utilizado indiscriminadamente, como um parâmetro estético.

O termo "combate" é utilizado em catorze leis, sobretudo quando se trata da instituição de programas de prevenção e tratamento ${ }^{3}$, que, geralmente, trazem a palavra em seus títulos. A opção pelo termo "combate" destoa da terminologia clássica utilizada para o campo da saúde e carrega consigo determinadas implicações políticas e socioculturais, contribuindo, possivelmente, para a discriminação dos sujeitos, já que não existe a obesidade em si, somente sujeitos

'Lei 9.259/06 (JUSBRASIL, 2011)

${ }^{3}$ Leis $4.319 / 09$; 5.031/09; 7.183/07; 12.283/06; 5.196/08; 3.666/02 (JUSBRASIL, 2011)

Movimento, Porto Alegre, v. 18, n. 02, p. 279-296, abr/jun de 2012. 
classificados como obesos. Só é possível combater um mal se ele estiver encarnado em alguém, que será enfrentado como inimigo.

Nas leis que tratam da instituição dos programas de tratamento e prevenção da obesidade, os procedimentos metodológicos para alcançar os objetivos propostos não são detalhados, referindo-se somente, em alguns casos, a palestras e folhetos informativos. De modo geral, deixa-se a cargo das Secretarias de Educação, Cultura e/ou Saúde estabelecerem as atividades que serão realizadas. Duas leis ${ }^{4}$ sugerem o convite, especificamente, de membros da Sociedade Brasileira de Pediatria e da Associação Brasileira de Estudos para a Obesidade (ABESO) para a participação na definição de tais procedimentos. Além disso, quinze das leis consultadas foram emitidas para garantir o direito à cirurgia bariátrica, aos medicamentos, à orientação nutricional e ao tratamento. Constata-se, com isso, não só uma grande influência política de certas classes profissionais, mas, principalmente, uma tendência jurídica e social de "instigação ao tratamento", (FOUCAULT, 2002).

Quando se trata de eventos, como um dia, uma semana ou um mês de "combate à obesidade", há, muitas vezes, um direcionamento para instituições de ensino. As avaliações e diagnósticos, assim como as intervenções, deverão ocorrer em período de aula e o objetivo seria conscientizar (orientar) sobre os "males" provocados pela obesidade infantil, suas causas, consequências e formas de evitá-la e tratá-la ${ }^{5}$. E, sob uma forma um pouco menos valorativa, "informar e conscientizar a comunidade sobre as causas e consequências da obesidade" (SANTA MARIA, 2011). Em todas, entretanto, as ações visam diagnosticar, classificar e encaminhar os alunos para o tratamento.

No caso da lei do Estado do Rio de Janeiro ${ }^{6}$, ainda há um respeito à autoridade dos responsáveis legais, que deverão autorizar antecipadamente qualquer participação de crianças e adolescentes

\footnotetext{
${ }^{4}$ Leis 3.666/02; 3.519/06 (JUSBRASIL, 2011).

${ }^{5}$ Leis 3.519/06 e 3.433/02 (JUSBRASIL, 2011).

${ }^{6}$ Lei 5.196/08 (JUSBRASIL, 2011).
}

Movimento, Porto Alegre, v. 18, n. 02, p. 279-296, abr/jun de 2012. 
no programa e na coleta de dados biométricos. Entretanto, as crianças e os adolescentes que estudam em alguns municípios ${ }^{7}$ serão submetidos a exames biométricos ou outros capazes de auxiliar o diagnóstico de sobrecarga ponderal ou da obesidade sem que a lei especifique que será necessário a autorização dos responsáveis.

Algumas das leis consultadas se referem, especificamente, à condição denominada obesidade mórbida, enquanto outras somente à obesidade. Entretanto, chama atenção aquelas ${ }^{8}$ que se referem a sobrepeso, sobrecarga ponderal ou propensão a desenvolvê-lo ou, simplesmente, a redução de peso ${ }^{9}$. Ou seja, mesmo nos casos que seriam oficialmente infrapatológicos, a sociedade, representada pelo poder executivo munido do discurso do risco, tem se outorgado o direito de intervenção. (FOUCAULT, 2002).

A acessibilidade também é um dos assuntos de muitas das legislações consultadas. Seis leis ${ }^{10}$ desobrigam o indivíduo considerado obeso, obeso mórbido ou simplesmente grande, a transpor a catraca do transporte coletivo urbano ou portas de segurança de agências bancárias. Duas ${ }^{11}$ tratam da disponibilização de equipamentos hospitalares adaptados. E há, ainda, aquelas que tratam da questão dos assentos ou poltronas especiais. Neste caso, o Estado de São Paulo $^{12}$ estabeleceu que duas poltronas especiais devem estar disponíveis no transporte público, cinema, teatros e casas de espetáculos. Já no Estado do Rio de Janeiro ${ }^{13}$, estabelecimentos de ensino e locais de realização de concursos públicos devem ter à disposição tantos assentos quanto necessários para o público considerado obeso. Em relação a casas de espetáculos estaduais ${ }^{14}$, $10 \%$ dos assentos deverão ser destinados a este público, enquanto

\footnotetext{
${ }^{7}$ Leis 5.130/08, 6.453/06, 790/06, 10.545/05 e 7.839/06 (JUSBRASIL, 2011)

${ }^{8}$ Leis $6.453 / 06,790 / 06,10.545 / 05,7.839 / 06$ e 5.130/08 (JUSBRASIL, 2011).

'Leis 4.319/09, 5.031/09, 7.183/07 e 12.283/06 (JUSBRASIL, 2011).

${ }^{10}$ Leis 3.211/99, 3.017/04, 3.542/04, 9.259/06, 8.120/05 e 7.498/10 (JUSBRASIL, 2011).

${ }^{11}$ Leis $5.038 / 07$ e 5.418/09 (JUSBRASIL, 2011).

${ }^{12}$ Lei 12.225/06 (JUSBRASIL, 2011).

${ }^{13}$ Lei 5.829/10 (JUSBRASIL, 2011).

${ }^{14}$ Leis $3.590 / 01$ e 5.288/08 (JUSBRASIL, 2011).
}

Movimento, Porto Alegre, v. 18, n. 02, p. 279-296, abr/jun de 2012. 
nos demais estabelecimentos voltados ao entretenimento há duas possibilidades: nos que possuírem mais de 200 assentos, $1 \%$ do total deverá ser adaptado, enquanto naqueles com menos de 200 deverá haver, ao menos, duas cadeiras adaptadas.

Pensando com Foucault (1996a), diríamos que essas leis possibilitam que as pessoas obesas se utilizem de ambientes públicos antes inacessíveis, mas também controlam, discriminam e segregam. Foucault (1996) afirma que em nossa sociedade haveria um outro princípio de exclusão, que não mais exclui ou interdita, mas separa e rejeita. Além disto, aquilo que para alguns é visto como uma conquista, para outros pode ser visto como injusto e pode suscitar mais discriminação. Um exemplo disso é um projeto de lei que vem causando controvérsia em Londrina, no Paraná, por pretender dar prioridade a obesos em filas, assim como é para idosos, deficientes e gestantes (SANTA, 2011).

Somente uma das leis consultadas - do Município de Matão/SP (2011) - tratava a respeito da discriminação às pessoas "portadoras de obesidade mórbida", ressaltando que o poder público municipal não poderá criar restrições de qualquer ordem contra as pessoas portadoras de obesidade mórbida para ingresso nas carreiras públicas municipais, mas com uma ressalva aos "cargos ou funções cujas atribuiçõos sejam incompatíveis com essa condição". Em relação aos estabelecimentos "que tenham sido condenados" por esse motivo, o município "cessará imediatamente o Alvará de Funcionamento".

\section{VeRDADES CRIADAS SOBRE A OBESIDADE}

As leis consultadas assinalam a existência de uma reivindicação por parte do poder público em intervir sobre a obesidade. Em quase todas as leis consultadas, as condições denominadas obesidade e obesidade mórbida são consideradas passíveis de intervenção e o acesso ao tratamento é garantido por lei. Além disso, algumas leis preveem a intervenção, embasada no argumento da prevenção, em casos infrapatológicos, como o exemplo do município gaúcho de Santa Maria, que estipula a possibilidade da "[...] realização de exame 
biométrico capaz de diagnosticar a presença de sobrepeso e indicativos à obesidade" em crianças (SANTA MARIA, 2011).

O uso do termo "combate à obesidade" apareceu como conceito transversal na análise feita da legislação brasileira. Disseminado e legalizado, o "combate à obesidade" tornou-se "um direito", desde que o cidadão se submeta à indicação e prescrição de tratamentos médicos, principalmente, os cirúrgicos e medicamentosos. No entanto, esse mesmo cidadão terá menos acesso aos direitos de saúde caso ele opte por um tratamento a longo prazo, que priorize, por exemplo, a prática de atividades físicas e esportivas. Um indicativo disso é que o Profissional de Educação Física não figura entre os interventores em nenhuma das legislações analisadas.

Constata-se, portanto, um funcionamento anômalo do poder judiciário - cuja principal característica seria a interdição, mas que passa a ser utilizado para instigar uma ação (FOUCAULT, 1996a). Como Foucault $(1996,2002)$ ressaltou, a perícia médica transformase no momento privilegiado para que o poder médico seja exercido e pressione o poder público a fazer o poder judiciário funcionar desse modo. O discurso patologizante ou medicalizado se infiltra no discurso jurídico e passa a justificar a "saúde persecutória" (CASTIEL; GUILAM, 2007; FOUCAULT, 2002).

Nesse contexto, os obesos se tornam alvo de uma disputa que envolve interesses econômicos, indústrias farmacêuticas, prestadores de serviços terapêuticos, políticos, entre outros. Assim, conforme assinala Junges, (2009, p.2), "[...] é fundamental estar atento ao crescente biopoder das empresas biotecnológicas que incentivam biopolíticas que identificam o direito à saúde simplesmente como direito a consumir produtos que simbolicamente vendem saúde". Esse direito, muito mais do que uma conquista é uma meta constituinte de uma moderna forma de governar, a qual Foucault $(2009 ; 2006)$ chamou de "governamentalidade". Nessa concepção de governar, a população "[...] aparecerá como sujeito das necessidades, de aspirações, mas também como objeto entre as mãos do governo, consciente diante do governo, do que ela quer, e inconsciente, também, do que lhe fazem fazer" (FOUCAULT, 2006, p.300). 
Nessa perspectiva, as ações e os discursos governamentais de "combate à obesidade" são também "exercícios de poder" que estão inseridos em uma "governamentalidade", tendo como horizonte a "noção do governo pela verdade" (FOUCAULT, 2009). Governo compreendido não como uma "instância suprema de decisões executivas e administrativas em um sistema estatal", mas como algo que envolve os "mecanismos e procedimentos destinados a conduzir os homens, a dirigir a conduta dos homens, a conduzir a conduta dos homens" (FOUCAULT, 2009).

A onipotência do discurso médico atravessa o corpo social e não raramente associa a obesidade a outros comportamentos indesejados como, por exemplo, o sedentarismo. Por tudo o que representam de riscos e de indesejáveis, sedentarismo e obesidade costumam estar na mira da maioria das campanhas e das políticas de saúde governamentais gerenciadas pelo biopoder. Assim, apesar de preservada as suas particularidades, obesos e sedentários ${ }^{15}$ constituem o alvo prioritário dos discursos biomédicos morais, espalhados pelo corpo social, em que "[...] o termo 'normal' tem brindado os valores de referência para toda e qualquer classificação" (PALMA; VILAÇA, 2010, p.7). Desse modo, mesmo se considerarmos as últimas reconfigurações da modernidade, como a possibilidade de estarmos transitando de uma "Sociedade Disciplinar", no sentido que assinou Foucault (1996a), para uma "Sociedade de Controle", conforme apontou Deleuze (1992), os discursos biomédicos normatizadores referentes à saúde, ao corpo e ao sujeito continuam a existir e a multiplicarem-se, renovando as suas estratégias e as suas máquinas discursivas ${ }^{16}$.

No conjunto da legislação brasileira encontramos cinco leis quatro de municípios paulistas e uma do Estado do Rio de Janeiro -

\footnotetext{
${ }^{15}$ Para uma melhor compreensão quanto aos discursos relativos ao sedentarismo, ao sujeito sedentário, ao governo e às práticas corporais consultar: "Exercício da informação: governo dos corpos no mercado da vida ativa" (FRAGA, 2006).

${ }^{16}$ Não realizamos maiores relações entre a obesidade moderna e a "Sociedade de Controle" (DELEUZE, 1992) por avaliarmos que isso demandaria a realização de um outro estudo. Todavia, algumas considerações específicas sobre a transição de uma "Sociedade Disciplinar" para uma "Sociedade de Controle" podem ser encontradas em Costa (2004).
} 
que propõem programas específicos para as instituições escolares. Sem entrar no mérito valorativo ou da possibilidade de sucesso dessas iniciativas, chamou-nos a atenção o fato de quatro dessas leis - a única exceção foi a carioca - não explicitarem a necessidade de um consentimento legal dos responsáveis pelos alunos menores de idade para que eles participem de iniciativas (programas), que envolvem a coleta de dados biométricos. Tais atitudes pressupõem que o poder público - governo municipal ou estadual - teria o direito de transferir para a instituição (escola) a responsabilidade ética e legal sobre a participação dos alunos nesses programas, prescindido de uma autorização por parte dos pais ou responsáveis. Ao nosso modo de ver, essa prerrogativa legal coloca a escola e o poder público numa delicada situação ética perante os pais e a sociedade.

O tema da saúde na escola e na Educação Física Escolar ${ }^{17}$ passou a receber um destaque maior após a sua inclusão como um dos temas transversais nos Parâmetros Curriculares Nacionais (PCN) de 1998 e, mais recentemente, a partir do Decreto $\mathrm{n}^{\circ}$ 6.289/ 07, que instituiu o Programa Saúde na Escola - PSE ${ }^{18}$. Enquanto os discursos da saúde naquele estariam alinhados com políticas de desconstrução do Estado de bem-estar social, neste voltariam a figurar com a promessa de manutenção dessas diretrizes (COOPER; SAYD, 2006). Em ambos os documentos, porém, haveria uma concepção de saúde numa perspectiva que Canguilhem (1995) denominou "normalizadora", referendada em classificações e comparações entre os sujeitos e tabelas de valores considerados ideais.

\footnotetext{
${ }^{17}$ Nos últimos anos temos acompanhado a proliferação de uma série de discursos que falam da relevância da Educação Física na saúde dos escolares. No entanto, Pich, Gomes e Vaz (2007) alertam para o fato de que a maioria desses discursos se assemelha à Educação Física dos anos 70 e 80.

${ }^{18}$ Os PCNs tratam a saúde na escola de uma forma genérica entre os temas transversais, em dois parágrafos. Se no primeiro parágrafo é possível identificar uma preocupação em conceituar a saúde situado-a no contexto social, no outro predomina uma concepção de saúde que aponta para a "capacitação" de cada um para o seu "autocuidado". Já os discursos presentes no PSE priorizam entre as suas metas uma série de avaliações dos alunos: avaliação clínica, avaliação nutricional, avaliação oftalmológica, avaliação auditiva e avaliação psicossocial.
} 
Analisando as leis, percebe-se também que a maior parte delas tende a considerar a obesidade como um problema individual, ao invés de social, conjectural ou mesmo histórico-cultural. Esse discurso que atrela a obesidade apenas a um problema individual ajuda a retirar a responsabilidade do Estado e fortalecer a velha e já denunciada estratégia governamental de "culpabilização da vítima" (MATIELLO JUNIOR; GONÇALES; MARTINEZ, 2008; FRAGA, 2006; PALMA; VILAÇA, 2010; BAGRICHEVSKY et al, 2007). Nesse caso, a estratégia discursiva aparece mesclada e, algumas vezes, referendada pelo poder jurídico, instigando uma maximização dos preconceitos perante os obesos.

Atualmente convivemos com práticas e discursos de diferentes naturezas que forjam em nossa subjetividade uma concepção do obeso como um sujeito preguiçoso, lento, pouco produtivo, sedentário e doente. Além disso, o sujeito obeso serve como um contra modelo, ele "[...] lembra aquela forma grotesca que serve de inspiração para piadas infantis ou para transmitir momentos de risos a um colega através de mais uma imagem 'hilária' enviada pela internet" (GOMES, 2006, p. 68).

Essa série normativa de estereótipos classificatórios atua como verdade proveniente de um biopoder socialmente criado pelos discursos e pelos saberes médicos, jurídicos, psicológicos e educativos (Educação Física), ajudando a instituir e a referendar no corpo social "a utopia da saúde perfeita", que "traz consigo a cruzada contra a obesidade" (GOMES, 2006, p. 66) ${ }^{19}$.

No corpus empírico analisado foi possível identificar uma tendência que ao excitar o "combate" (a perseguição) à obesidade também contribui para estereotipar os obesos. Em parte, isso resulta do próprio conceito de obesidade, - gordura corporal excessiva -

\footnotetext{
${ }^{19} \mathrm{~A}$ utopia da saúde perfeita, proveniente do biopoder, é incompatível com a perspectiva do "cuidado de si", apontado por Foucault (1984; 1985) e também se afasta da noção de "grande saúde" assinalada por Nietzsche (1983). Algumas aproximações do conceito de "grande saúde" com o campo de a Educação Física ver: (ALVES; CARVALHO, 2010).
} 
que traz consigo um juiz do corpo e da vida, que se conclama o direito e o dever de determinar a massa corporal ou o IMC ideal, normal e saudável, para os indivíduos contemporâneos.

\section{CoNSIDERAÇõES FINAIS}

A partir do estudo que realizamos, foi possível concluir que predomina na legislação brasileira uma preocupação em diagnosticar/ classificar, recomendar e prescrever tratamentos médicos como estratégia para "combater" a obesidade. Por outro lado, ainda são escassas as leis preocupadas em garantir os direitos sociais e constitucionais dos cidadãos classificados como obesos.

Dentre os poucos casos em que houve indicações legais sinalizando para a garantia de isonomia, como no caso do município de Matão (2011) em São Paulo, prevalece a possibilidade de interpretações jurídicas que dificultam a implementação das mesmas. Os concursos públicos são exemplos desse fato, já que as considerações a respeito da incompatibilidade da função têm propiciado interpretações que retiram os direitos desses cidadãos como foi o caso ocorrido no Brasil e referenciado na introdução deste trabalho. Em parte, isso ocorre porque a legislação brasileira carece de leis inseridas em uma perspectiva da "bioética de saúde pública", que pressupõe uma "proteção dos direitos sociais prestativos" (JUNGES, 2009, p. 14).

Ressalta-se, ainda, que algumas instituições privadas e públicas (como ocorreu no episódio do concurso público) vêm apropriandose dos discursos da área da saúde, que consideram doentes os sujeitos classificados como obesos ou obesos mórbidos, para referendar juridicamente práticas segregacionistas disfarçadas pelos argumentos da eficiência, da competência e da produtividade. O preconceito e a discriminação (velada e/ou explicita) aparecem também na linguagem jurídica que predomina na legislação brasileira sobre o tema, como evidencia o uso recorrente da expressão "combate à obesidade", conceito que em nossa sociedade possui uma tradição de ser utilizado em campanhas públicas como: "combate ao crime organizado", 
"combate à corrupção"; "combate ao tráfico de drogas"; "combate à prostituição infantil"; "combate à pedofilia", etc.

O diagnóstico que realizamos sobre a maneira como a obesidade é tratada na jurisdição brasileira mostrou, ainda, que o tema entrecruza diferente áreas do conhecimento, como Direito, Medicina, Sociologia, Ética e Educação Física. Nessa perspectiva, assinalamos a pertinência da obesidade ser tratada não apenas como uma (perigosa) patologia, digna de ser "combatida" e os obesos de serem caçados, mas sim como uma questão política, cultura e social - como uma questão de governo, "governo dos vivos", "governo de si e dos outros" (FOUCAULT, 2009). Por fim, pela atualidade e relevância que o tema suscita, consideramos importante a realização de outros estudos, principalmente com o objetivo de aprofundar as relações desta temática com o campo da Educação Física. 


The combat against obesity: brazilian
legislation's analysis.
Abstract: This essay had as purpose to analyze how
the obesity is being approached in the Brazilian
legislation. It was used the Speech Analysis (AS) in
the Foucaultiana perspective as methodology. The
empirical corpus consisted in a search for the key-
words "obesity" and "overweight" in the web site
Jusbrasil, where 46 rules were found. The analysis
of this material indicated that it stands out a tendency
to blame the obese, instigation to medical treatment
and a discursive emphasis on the "combat" against
obesity. It was found little concern on the guarantee
of the rights of the group.
Keywords: obesity. legislation as topic. humanities.
Human rights

La lucha contra la obesidad: un análisis de la legislación brasileña

Resumen: Este ensayo tuvo como objetivo analizar como la obesidad está siendo tratada em la legislación brasileña. Como metodología se utilizó el Análisis de Discurso $(A D)$ en la perspectiva foucaultiana. El corpus empírico se constituye de una búsqueda por las palabras-claves obesidad y exceso de peso en el site Jusbrasil, donde fueron encontradas 46 leyes. El análisis de este material mostró que sobresale una tendencia para la culpabilidad del sujeto obeso, incitación al tratamiento médico y el énfasis discursivo al "combate" de la obesidad. Al contrario, se le dio poca atención en la garantía de los derechos del grupo. Palabras clave: Obesidad. legislación como asunto. Ciencias humanas. Derechos humanos.

\section{REFERÊNCIAS}

ALVES, Flávio Soares; CARVALHO, Yara Maria de. Práticas corporais e grande saúde: um encontro possível. Movimento, Porto Alegre, v. 16, n. 4, p. 229 - 244, out./dez., 2010. Disponível em: <http://seer.ufrgs.br/Movimento/article/view/13280/ 10853>. Acesso em: 10 abr. 2011.

BAGRICHEVSKY, M.; et al. Sedentário 'sem-vergonha', saudável 'responsável'? Problematizando a difusão do 'estilo de vida ativo' no campo sanitário. In: BAGRICHEVSKY, Marcos; PALMA, Alexandre; ESTEVÃO, Adriana (Org.). A saúde em debate na Educação Física. Ilhéus: Editus, 2007. v. 3. p. 209-230. 
CANGUILHEM, Georges. O normal e o patológico. Rio de Janeiro: Forense, 1995.

CASTIEL, Luis David; GUILAM, Maria Cristina Rodrigues. A saúde persecutória: à espera dos riscômetros portáteis. Interface, Botucatu, v. 11, n. 21, p. 159-161, jan./abr. 2007. Disponível em: <http://www.scielo.br/scielo.php?script= sci_arttext\&pid=S1414-32832007000100015>. Acesso em: 13 nov. 2011.

COLDITZ, Graham A.; MARIANI, Anna. O custo da obesidade e do sedentarismo nos Estados Unidos. In: BOUCHARD, C. Atividade física e obesidade. São Paulo: Manole, 2003. p. 63-75.

COOPER, Carlos Leal Ferreira: SAYD, Jane Dutra. Concepções de saúde nos parâmetros curriculares nacionais. In: BAGRICHEVSKY, Marcos; PALMA, Alexandre; ESTEVÃO, Adriana (Org). A saúde em debate na educação física. Blumenau: Nova Letra, 2006. v. 2

COSTA, Rogério da. Sociedade de Controle. São Paulo em Perspectiva, São Paulo, v. 18 n. 1, p. 61-67, jan./mar. 2004. Disponível em: <http://www.seade.gov.br/ produtos/spp/v18n01/v18n1_18.pdf>. Acesso em: 1ํ maio 2011.

DELEUZE, Gilles. Post-Scriptum sobre as Sociedades de Controle. In:

Conversações. Rio de Janeiro: Ed. 34, 1992. p. 219-226.

FOUCAULT, Michel. Os anormais: curso no Collège de France. São Paulo: Martins Fontes, 2002.

A Arqueologia do Saber. 4. ed. Rio de Janeiro: Forense Universitária, 1995.

A "Governamentalidade" In: MOTTA, Manoel Barros da (Org.). Michel Foucault, Estratégia, poder-saber. Rio de Janeiro: Forense Universitária, 2006. p. 281-305. (Ditos e escritos, 4)

Do governo dos vivos: Curso no Collége de France, 1979-1980: aulas de 09 e 30 de janeiro de 1980. São Paulo: Centro de Cultura Social, 2009. Disponível em: <http://www.ccssp.org/ccs/index.php?option=com_content $\&$ view= article\&id=82: do-governo-dos-vivos\&catid=44:padrao\&Itemid=65/>. Acesso em: 15 mar. 2011. Graal, 1984.

História da Sexualidade, 2: o uso dos prazeres. Rio de Janeiro: Edições História da Sexualidade, 3: o cuidado de si. Rio de Janeiro: Edições Graal, 1985.

Microfísica do poder. 12. ed. Rio de Janeiro, Graal, 1996a.

Nascimento da biopolítica. São Paulo: Martins Fontes, 2008. 
O nascimento da clínica. 5. ed. Rio de Janeiro: Forense Universitária, 1998.

A ordem do discurso. 10. ed. São Paulo: Loyola, 1996.

FRAGA, Alex Branco. Exercício da informação: governo dos corpos no mercado da vida ativa. Campinas, SP: Autores Associados, 2006.

GOMES, Ivan Marcelo. Obesidade como metáfora contemporânea: uma cruzada saudável em nome do consumo e do risco: Movimento, Porto Alegre, v. 12, n. 3, p. 45-71, set. 2006. Disponível em: <http://seer.ufrgs.br/Movimento/article/view/ 2909/1545>. Acesso em: 12 maio 2011.

GREGOLIN, Maria do Rosário. Foucault e Pêcheux na construção da análise do discurso: diálogos e duelos. São Carlos: ClaraLuz, 2004.

GUGLINSKI, Vitor Vilela. Candidatos obesos, concursos públicos e o peso da justiça. Unieducar, Fortaleza, v. 11, n. 4820, 24 fev. 2011. Disponível em: <http:// www.unieducar.org.br/artigos.asp?cod=2\&id=1301>. Acesso em: 19 fev. 2011.

HALPERN, Alfred et al. (Org.). Obesidade. São Paulo: Lemos, 1998.

JUNGES, José Roque. Direito à Saúde, biopoder e bioética. Interface: Comunic., Saúde, Educ., v. 13, n. 29, p.285-295, abr./jun. 2009. Disponível em: <http:// www.interface.org.br>. Acesso em: 12 jan. 2011.

JUSBRASIL. Disponível em: <http://www.jusbrasil.com.br/noticias>. Acesso em: 2 abr. 2011.

MATÃO. Prefeitura Municipal. Lei n. 3864, de 17 de Julho de 2007. Veda qualquer forma de discriminação aos portadores de obesidade mórbida no âmbito do Município de Matão e dá outras providências. Matão, SP, 2007. Disponível em: <http:// www.jusbrasil.com.br/legislacao/653012/lei-3864-07-matao-sp>. Acesso em: 24 mar. 2011.

MATIELLO JUNIOR, Edgard; GONÇALVEZ, Aguinaldo; MARTINEZ, Jéssica Félix Nicácio. Superando riscos na atividade física relacionada à saúde. Movimento, Porto Alegre, v. 14, n. 1, p. 39-61, jan./abr. de 2008. Acesso em: 11 mar. 2011.

NIETZSCHE, Friedrich Wilhelm. Os pensadores: obras incompletas. 3. ed. São Paulo: Abril Cultural, 1983.

OLIVEIRA JUNIOR, Eudes Quintino. A discriminação do obeso. Disponível em: <http://www.jusbrasil.com.br/noticias/2600471/a-discriminacao-do-obeso>. Acesso em: 7 maio 2011.

OLIVER, J. Eric. Fat Politics: the real story behind America's obesity epidemic. Nova York: Oxford University, 2006.

ORGANIZAÇÃO MUNDIAL DA SAÚDE. Obesidade: prevenindo e controlando a epidemia global. São Paulo: Roca, 2004. 
PALMA, Alexandre, VILAÇA, Murilo Mariano. O sedentarismo da epidemiologia. Rev. Bras. Cienc. Esporte, Campinas, v. 31, n. 2, p. 105-119, 2010. Disponível em: <http://www.rbceonline.org.br/revista/index.php/RBCE>. Acesso em: 14 abr. 2011.

PELBART, Peter Pál. Vida Capital: ensaios de biopolítica. São Paulo: Iluminuras, 2003.

PICH, Santiago, GOMES, Ivan Marcelo, VAZ, Alexandre Fernandez. Mercadorização biopolítica: sobre escolhas saudáveis em tempos de consumo. In: BAGRICHEVSKY, Marcos; PALMA, Alexandre; ESTEVÃO, Adriana (Org.). A saúde em debate na Educação Física. Ilhéus: Editus, 2007. v. 3, p. 187-208.

REAVALIADOS, professores são liberados em concurso. Folha de São Paulo, São Paulo, 6 mar. 2011. Seção Cotidiano. Disponível em: <http:// www1.folha.uol.com.br/cotidiano/885179-reavaliados-professores-obesos-saoliberados-em-concurso.shtml>. Acesso em: 10 abr. 2011.

SANTA MARIA. Prefeitura Municipal. Lei n. 5130, de 07 de Julho de 2008. Institui no Município de Santa Maria o Mês da Saúde Preventiva da Obesidade Infantil e dá outras providências. Disponível em: <http://www.jusbrasil.com.br/legislacao/ 908768/lei-5130-08-santa-maria-0>. Acesso em: 24 mar. 2011.

SANTA, Amanda de. Lei municipal quer dar prioridade para obesos nas filas em Londrina. Jornal de Londrina, Londrina, 25 dez. 2010. Disponível em: <http:// www.jornaldelondrina.com.br/cidades/conteudo.phtml?id=1080568>. Acesso em: 24 mar. 2011.

\section{Auxílio CAPES}

Endereço para correspondência:

Cezar Barbosa Santolin

Rua Sete de Setembro, 913 - Centro

CEP 85960-000 - Marechal Cândido Rondon/PR - Brasil

Luiz Carlos Rigo

Rua Gonçalves Chaves 3063 apartamento 502 Bloco B

CEP. 96010560 
